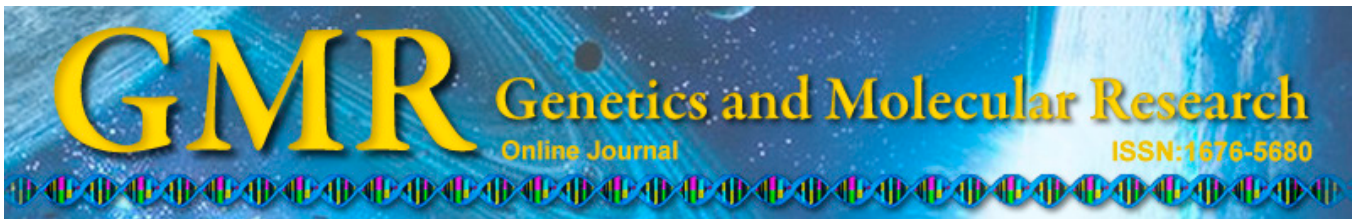

\title{
Evolutionary dynamics of rDNA genes on chromosomes of the Eucinostomus fishes: cytotaxonomic and karyoevolutive implications
}

\author{
L.L. Calado ${ }^{1}$, L.A.C. Bertollo ${ }^{2}$, M.B. Cioffi ${ }^{2}$, G.W.W.F. Costa ${ }^{1}$, \\ U.P. Jacobina ${ }^{1}$ and W.F. Molina ${ }^{1}$ \\ ${ }^{1}$ Departamento de Biologia Celular e Genética, Centro de Biociências, \\ Universidade Federal do Rio Grande do Norte, Natal, RN, Brasil \\ ${ }^{2}$ Departamento de Genética e Evolução, Universidade Federal de São Carlos, \\ São Carlos, SP, Brasil \\ Corresponding author: W.F. Molina \\ E-mail: molinawf@yahoo.com.br
}

Genet. Mol. Res. 13 (4): 9951-9959 (2014)

Received February 14, 2014

Accepted May 27, 2014

Published November 27, 2014

DOI http://dx.doi.org/10.4238/2014.November.27.24

\begin{abstract}
Several chromosomal features of Gerreidae fish have been found to be conserved. In this group, it is unclear whether the high degree of chromosomal stasis is maintained when analyzing more dynamic regions of chromosomes, such as rDNA sites that generally show a higher level of variability. Thus, cytogenetic analyses were performed on 3 Atlantic species of the genus Eucinostomus using conventional banding (C-banding, Ag-NOR), AT- and GC-specific fluorochromes, and fluorescence in situ hybridization mapping of telomeric sequences and $5 \mathrm{~S}$ and $18 \mathrm{~S}$ rDNA sites. The results showed that although the karyotypical macrostructure of these species is similar $(2 \mathrm{n}=48$ chromosomes, simple Ag-NORs seemingly located on homeologous chromosomes and centromeric heterochromatin pattern), there are differences in the positions of rDNA subunits $5 \mathrm{~S}$
\end{abstract}


and $18 \mathrm{~S}$. Thus, the ribosomal sites have demonstrated to be effective cytotaxonomic markers in Eucinostomus, presenting a different evolutionary dynamics in relation to other chromosomal regions and allowing access to important evolutionary changes in this group.

Key words: Chromosome evolution; Gene synteny; Karyotype stasis; Mojarras

\section{INTRODUCTION}

The family Gerreidae comprises 44 species of small- to medium-sized fish living in shallow coastal estuarine waters, with wide distribution in tropical and subtropical latitudes (Nelson, 2006). In some areas they constitute typical groups of mangrove environments, where they represent an abundant and important component of the food chain in areas of high biological productivity (Ramírez-Luna et al., 2008). Some species have been considered potential candidates for intensive cultivation (Calado et al., 2013). In the Atlantic waters, this group of fish includes the genera Diapterus, Eugerres, Eucinostomus, Gerres, and Ulaema (Eschmeyer, 1998), with cytogenetic data available only for the first 3 of these genera.

Karyotypic studies are useful tools in taxonomy and identification of relationship patterns and phylogenies, particularly in groups with cryptic taxonomic characters in some life stages. Previous cytogenetic analyses of Eucinostomus, Diapterus, and Eugerres have demonstrated the potential of Ag-NOR sites for taxonomic discrimination (Ruiz-Carus and UribeAlcocer, 2004) and of the mapping of $18 \mathrm{~S}$ and 5S rDNA sequences in the species identification in this family (Calado et al., 2013). The chromosomal mapping of ribosomal sequences, which are dynamic regions able to spread within the genome (Shishido et al., 2000), has received increasing attention for their usefulness in indirect identification of karyotype diversification in Perciformes, especially for species identification (Molina et al., 2012a,b) and/or fish stocks.

Thus, in this study, cytogenetic data obtained from 3 species of the genus Eucinostomus, silver mojarras E. argenteus (Baird and Girard, 1855), jenny mojarras E. gula (Quoy and Gaimard, 1824), and flagfin mojarras E. melanopterus (Bleeker, 1863), were determined using different classical and molecular cytogenetic methods, including dual-color fluorescence in situ hybridization (FISH) chromosomal mapping of $18 \mathrm{~S}$ and $5 \mathrm{~S}$ rDNA sites and telomeric (TTAGGG) ${ }_{n}$ sequences. The data revealed the dynamics of the $18 \mathrm{~S}$ and $5 \mathrm{~S}$ ribosomal units in the genome of Eucinostomus species resulting from chromosomal rearrangements not detectable by macrostructural chromosome analysis. Thus, these rDNA sites are effective markers for increasing the understanding of evolutionary processes occurring in this group.

\section{MATERIAL AND METHODS}

\section{Specimens and chromosome preparations}

Twenty-seven individuals of 3 species of Eucinostomus (Gerreidae) were analyzed, including E. argenteus $(\mathrm{N}=10,6$ males, 4 females), E. gula $(\mathrm{N}=8,5$ males, 3 females), and E. melanopterus $(\mathrm{N}=9,4$ males, 5 females), collected from the base levels of the Cunhaú River $\left(6^{\circ} 18^{\prime} 26.97^{\prime \prime} \mathrm{S} 35^{\circ} 01^{\prime} 55.45^{\prime \prime} \mathrm{W}\right)$ in Canguaretama, and from the Açu River in Guamaré $\left(5^{\circ} 05^{\prime} 42.33^{\prime \prime S} 36^{\circ} 16^{\prime} 31.66^{\prime \prime} \mathrm{W}\right)$, in the State of Rio Grande do Norte, which is the northeast 
region of Brazil.

Prior to chromosome preparations, the specimens were subjected to in vivo mitotic stimulation for $24 \mathrm{~h}$, by intramuscular and intraperitoneal inoculation of complexes of bacterial and fungal antigens (Molina et al., 2010). The specimens were anesthetized with clove oil (eugenol) and euthanized for the removal of kidney tissue. Metaphase chromosomes were obtained from cell suspensions of fragments of the anterior kidney using an in vitro method of short duration (Gold et al., 1990). Cell suspensions were dripped onto slides coated with a film of distilled water heated to $60^{\circ} \mathrm{C}$. Approximately 30 metaphases were analyzed in each specimen to determine the chromosome number and morphology. The best metaphases were photographed using an Olympus BX50 epifluorescent microscope with a digital camera Olympus DP73 (Tokyo, Japan).

\section{Chromosome banding}

The heterochromatic regions and NOR sites were identified using the methods described by Sumner (1972) and Howell and Black (1980), respectively. GC-rich chromosomal regions were evidenced by the chromomycin $\mathrm{A}_{3}$ fluorochrome ( $\left.\mathrm{CMA}_{3}\right)$, using 4', 6-diamidino2-phenylindole (DAPI) as counterstain (Schweizer and Loidl, 1987). Briefly, 3-day-old slides were stained with $0.1 \mathrm{mg} / \mathrm{mL} \mathrm{CMA}_{3}$ for $60 \mathrm{~min}$ and restained with $1 \mu \mathrm{g} / \mathrm{mL}$ DAPI for $30 \mathrm{~min}$. Next, the slides were mounted in glycerol:Mcllvaine buffer, $\mathrm{pH} 7.0$ (1:1), and incubated for 3 days at $4{ }^{\circ} \mathrm{C}$ before analysis with an epifluorescence microscope under appropriate filters.

\section{FISH procedures}

FISH using 5S rDNA, 18S rDNA, and telomeric was performed with minor modifications of the method recommended by Pinkel et al. (1986). The 5S and 18S rDNA probes, containing 200 and $1400 \mathrm{bp}$, respectively, were obtained by polymerase chain reaction (PCR) from the nuclear DNA of Prochilodus lineatus (Hatanaka and Galetti, 2004), using the primers A: 5'-TAC GCC CGA TCT CGT CCG ATC-3' and B: 5'-CAG GCT GGT ATG GCC GTA AGC-3' (Pendás et al., 1995), NS1: 5'-GTA GTC ATA TGC TTG TCT C-3', and NS8: 5'-TCC GCA GGT TCA CCT ACG GA-3' (White et al., 1990), respectively. The telomeric DNA sequence (TTAGGG) ${ }_{n}$ was also used as a probe, previously generated by PCR (PCRDIG Probe Synthesis Kit, Roche) using (TTAGGG) ${ }_{5}$ and (CCCTAA) ${ }_{5}$ as primers (Ijdo et al., 1991). The $5 \mathrm{~S}$ and $18 \mathrm{~S}$ rDNA sequences were detected by dual-color FISH. The $5 \mathrm{~S}$ and $18 \mathrm{~S}$ rDNA probes were labeled with biotin-14-dATP and digoxigenin-11-dUTP, respectively, by nick translation according to manufacturer recommendations (Roche, Mannheim, Germany). Chromosomes were treated with $20 \mathrm{mg} / \mathrm{mL}$ DNAse-free RNAse in $2 \mathrm{X} \mathrm{SSC}$ at $37^{\circ} \mathrm{C}$ for $1 \mathrm{~h}$ with $0.005 \%$ pepsin in $10 \mathrm{mM} \mathrm{HCl}$ at $37^{\circ} \mathrm{C}$ for $10 \mathrm{~min}$, fixed with $1 \%$ formaldehyde for $10 \mathrm{~min}$, and then dehydrated in an alcohol series. Chromosomes were then denatured in $70 \%$ formamide $/ 2 \mathrm{X} \mathrm{SSC}$ at $72^{\circ} \mathrm{C}$ for $5 \mathrm{~min}$. The hybridization solution consisted of $50 \%$ formamide, $2 \mathrm{X} \mathrm{SSC}, 10 \%$ dextran sulfate, and $5 \mathrm{ng} / \mu \mathrm{L}$ denatured probe. After hybridization for $18 \mathrm{~h}$ at $37^{\circ} \mathrm{C}$, the slides were washed in $15 \%$ formamide $/ 0.2 \mathrm{X} \mathrm{SSC}$ at $42^{\circ} \mathrm{C}$ for 20 min, $0.1 \mathrm{X} \mathrm{SSC}$ at $60^{\circ} \mathrm{C}$ for $15 \mathrm{~min}$, and Tween $200.5 \% / 4 \mathrm{X} \mathrm{SSC}$ at room temperature. The hybridization signals of digoxigenin-labeled probes were detected using anti-digoxigeninrhodamine conjugate (Roche); and anti-avidin fluorescein isothiocyanate conjugate (Sigma, St. Louis, MO, USA) was used for the biotinylated probes. The chromosomes were counterstained with $1.5 \mu \mathrm{g} / \mathrm{mL}$ Vectashield/DAPI (Vector Laboratories, Burlingame, CA, USA). 


\section{RESULTS}

E. argenteus, E. gula, and E. melanopterus have $2 \mathrm{n}=48$ acrocentric chromosomes $(\mathrm{FN}=48$; Figure 1a, $b$, and c). The karyotypes are quite symmetrical with little size difference between the pairs.

Conspicuous heterochromatic blocks were observed in the pericentromeric regions of the chromosomes in the 3 species analyzed (Figure 1a, b, and c; right column). However, the heterochromatic segments more expanded in E. argenteus than in the other species (Figure 1b; right column). In E. argenteus, the pericentromeric heterochromatin was GC-positive both in ribosomal sites and most chromosome pairs (Figure 2a). Ag-NOR sites were identified in all 3 species only on chromosome pair 22, although in varying positions, since they were interstitially located in E. argenteus and E. melanopterus and in the terminal position in E. gula (Figure 2b, c, and d). A precise correlation was observed between the Ag-NORs and $\mathrm{CMA}_{3}^{+}{ }^{+}$DAPI ${ }^{-}$sites in the 3 species (Figure 2b, c, and d). FISH with telomeric probes (TTAGGG) ${ }_{n}$ showed markings exclusively in the terminal regions of almost all the chromosomes (Figure $2 \mathrm{e}, \mathrm{f}$, and $\mathrm{g}$ ).

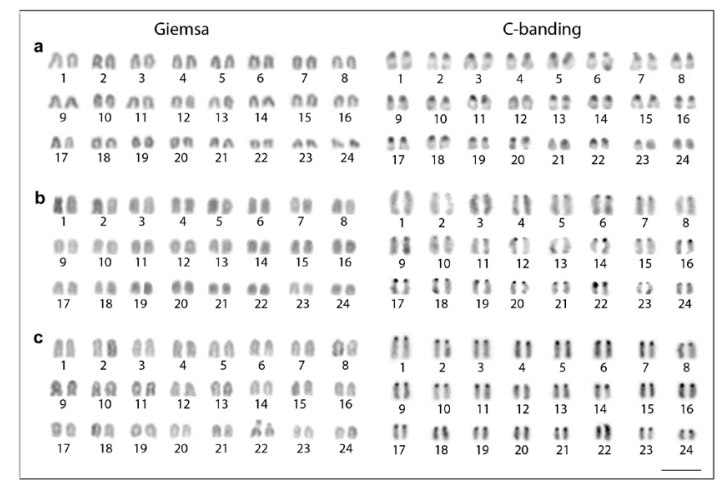

Figure 1. Karyotypes of Eucinostomus argenteus (a), E. gula (b), and E. melanopterus (c) with conventional staining and C-banding. Bar $=5 \mu \mathrm{m}$.

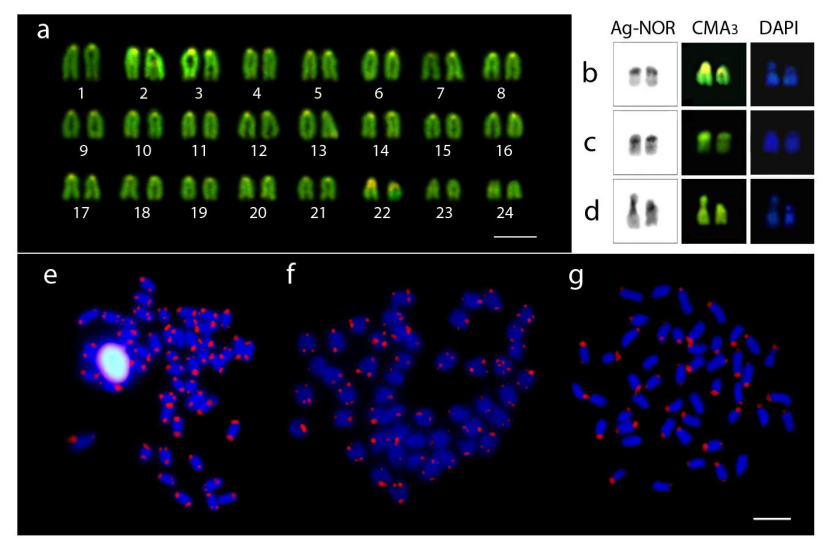

Figure 2. Fluorescent pattern of Eucinostomus argenteus chromosomes (a) stained with $\mathrm{CMA}_{3}$ showing GC-rich pericentromeric heterochromatin on most chromosome pairs. Detail of the nucleolar organizer pair (pair 22) subjected to silver impregnation and staining with base-specific fluorochrome $(\mathbf{b}, \mathbf{c}, \mathbf{d})$ and mapping of telomeric sequences $\left(\right.$ TTAGGG $_{n}(\mathbf{e}, \mathbf{f}, \mathbf{g})$ in E. argenteus $(\mathbf{b}, \mathbf{e})$, . gula $(\mathbf{c}, \mathbf{f})$, and E. melanopterus $(\mathbf{d}, \mathbf{g})$, respectively. Bars $=5 \mu \mathrm{m}$. 
Mapping of 5S rDNA subunits showed single sites in the 3 species, but located on different chromosomes. In E. argenteus, these sites were located interstitially on pair 11 . In $E$. gula, they were located in the terminal position of the short arms on pair 6, and in E. melanopterus they were located in interstitial position and colocalized with the 18S rDNA sites on the long arm of pair 22 (Figure 3a, b, and c).

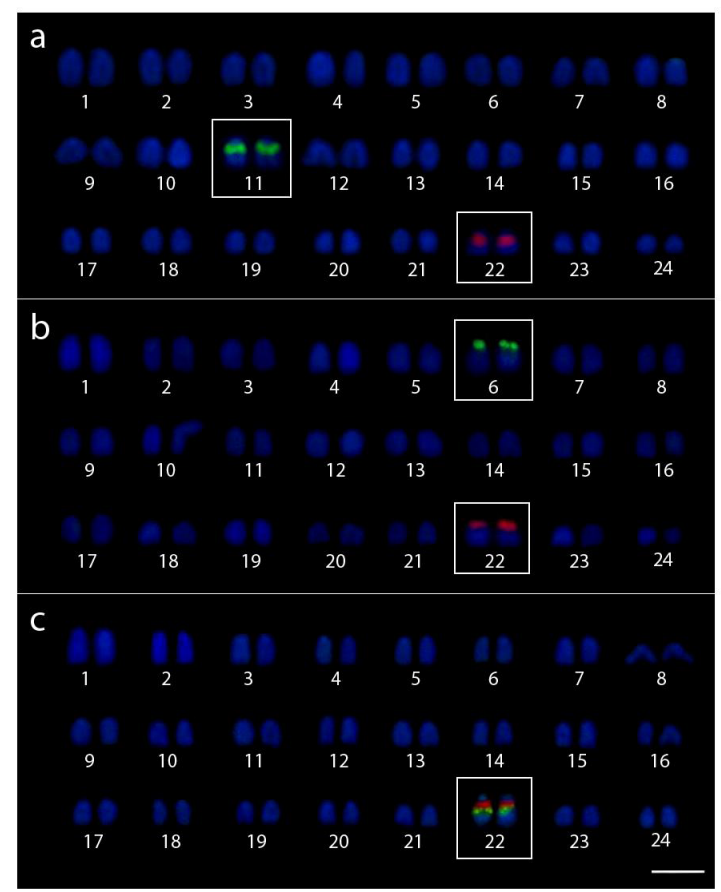

Figure 3. Location of $18 \mathrm{~S}$ (red) and $5 \mathrm{~S}$ (green) ribosomal genes using dual-color FISH mapping in Eucinostomus argenteus (a), E. gula (b), and E. melanopterus $(\mathbf{c})$. Bar $=5 \mu \mathrm{m}$.

\section{DISCUSSION}

Eucinostomus species show a highly conserved karyotypic macrostructure $(2 \mathrm{n}=48$, $\mathrm{FN}=48)$. Substantial intrageneric similarity has also been observed among mojarras of the genera Diapterus and Eugerres (Calado et al., 2013). This karyotypic pattern, which is similar to the putative basal karyotype in Perciformes (Molina, 2007; Motta-Neto et al., 2011), is not only present in representatives of Gerreidae (Ruiz-Carus and Uribe-Alcocer, 2004; Calado et al., 2013), but also frequently observed among Perciformes (Arai, 2011). Together with macrostructural features, some chromosomal traits of Eucinostomus appear to be highly conserved, such as simple $\mathrm{Ag}-\mathrm{NOR}$ sites $\left(\mathrm{C}^{+} / \mathrm{GC}^{+} / \mathrm{DAPI}\right)$ and pericentromeric heterochromatin regions.

Marine Perciformes exhibit a high karyotypic stability in some groups, with evidence of karyotypic stasis (Molina, 2007), where the cytogenetic differences fall short of phenotypic variation between closely related species (Motta-Neto et al., 2012). In contrast, the karyotypes of some Perciformes families, although subjected to a slower evolutionary rate regarding the fixation of structural rearrangements, have revealed some hypervariable chromosomal 
regions, particularly those represented by ribosomal sites or positions adjacent to them (Affonso and Galetti Jr., 2005). Thus, in groups of fish with higher karyotypic stability, the mapping of the ribosomal has been particularly effective for identifying and quantifying chromosome dynamics (Motta-Neto et al., 2012), particularly among cogeneric species, as suggested by the Eucinostomus species analyzed in this study. In fact, analyses involving the mapping of $18 \mathrm{~S}$ and $5 \mathrm{~S}$ sequences and characterization of GC-rich regions in these species revealed diagnostic cytogenetic markers, enabling identification of unique chromosomal differences between them.

GC-positive extra-NOR heterochromatic segments in E. argenteus, which are not present in E. gula and E. melanopterus, represent a peculiar characteristic of this species. This condition, although unusual, has been reported in some fish species (Affonso and Galetti Jr., 2005; Molina et al., 2012a,b), suggesting that the high GC-rich content around the karyotype favors chromosomal rearrangements (Martinez et al., 2011). Aside from this characteristic derived from heterochromatin in E. argenteus (GC-rich), all species presented mainly centromeric heterochromatin. Such heterochromatin distribution pattern is considered to be conserved and widespread in Perciformes, particularly in marine groups (Molina, 2007).

Less conserved, the mapping with $5 \mathrm{~S}$ and $18 \mathrm{~S}$ ribosomal sequences revealed interspecific variation thus demonstrating that ribosomal sites may be effective cytotaxonomic markers or indicate the occurrence of chromosomal rearrangements, particularly among species that show low karyotypic diversity (Motta-Neto et al., 2012). Thus, although 18S rDNA sites are single and apparently located on homeologous chromosome pairs in the 3 species analyzed (pair 22), they have different positions on the chromosomes: at the interstitial position in $E$. argenteus and E. melanopterus and at the terminal position of the short arm in E. gula; these results suggest intrachromosomal rearrangements. The activity of NORs on a single chromosome pair may have provided a rare and casual interstitial colocalization of the $18 \mathrm{~S}$ and $5 \mathrm{~S}$ genes in E. melanopterus. In fish, $5 \mathrm{~S}$ and $18 \mathrm{~S}$ rDNA multigene families are most often located on different chromosome pairs, which appear to represent the most common and possibly basal condition for ribosomal gene arrangement (Martins and Galetti Jr., 1999). Thus, they may evolve independently and are subject to individual selective pressure (Amarasinghe and Carlson, 1998). Occasionally, in Perciformes, both the 5S and 18S rDNA sites may be diversified (Motta-Neto et al., 2012), standing out not only as efficient species markers but also as population markers (Lima-Filho et al., 2012), and may be involved in chromosome rearrangements (Jacobina et al., 2013).

In several fish species, the 5S rDNA sites are located in interstitial position on the chromosomes, as in salmonids (Fujiwara et al., 1998), anostomids (Martins and Galetti Jr., 2000), and parodontids (Vicente et al., 2001), among many others. In fact, this location is also the most common among Eucinostomus species. However, it remains unclear whether this condition is a plesiomorphic characteristic of this particular genus. Further studies should map these genes in a larger number of species.

Eventually, the $5 \mathrm{~S}$ and $18 \mathrm{~S}$ sites may exhibit synteny and become located on the same chromosome. Although this spatial conformation is unusual, it has been observed in some species of fish, including Salmo salar (L. 1758) (Morán et al., 1994), Oreochromis niloticus (L. 1758) (Pendás et al., 1994), Triportheus nematurus (Kner, 1858) (Diniz et al., 2008), and Hoplias malabaricus (Bloch, 1794) (Cioffi et al., 2009). The syntenic adjacent location detected in E. melanopterus indicates an autapomorphic condition for this species, since the dual-color 
FISH mapping in other species of this and other Gerreidae genera reveal a non-syntenic position of ribosomal genes (Calado et al., 2013). Interestingly, in E. argenteus and E. gula, both ribosomal sites are located on separate chromosomes, exhibiting variations in intrachromosomal location (terminal, interstitial), whereas in E. melanopterus they are interstitially colocated on a single pair. These various physical arrangements of rDNA sites demonstrate their relative mobility in the genome, unlike other chromosomal regions such as the centromeric and telomeric sequences, which seem to be less dynamic in evolutionary terms.

Based on the position of the ribosomal sequences in the karyotypes of the 3 species of Eucinostomus, as with the dual-color FISH mapping data in species of Diapterus and Eugerres, 3 stages of chromosomal location of ribosomal sites of Gerreidae could be distinguished (Figure 4). The first pattern, observed in E. argenteus, is represented by both $5 \mathrm{~S}$ and $18 \mathrm{~S}$ sites in interstitial positions on different chromosome pairs. This pattern may correspond to the baseline condition of Gerreidae, given its greater frequency among species and a possible advantage that the interstitial location of ribosomal genes may protect against disruptive chromosomal rearrangements (Martins and Galetti Jr., 1999). Thus, the second pattern, present only in E. gula among the Gerreidae, corresponds to a derived condition, represented by both $5 \mathrm{~S}$ and $18 \mathrm{~S}$ sites in the terminal position on different chromosomes. Finally, the rare third pattern corresponds to an autapomorphy in E. melanopterus, represented by both $5 \mathrm{~S}$ and $18 \mathrm{~S}$ sites colocated on a single pair in the interstitial position.

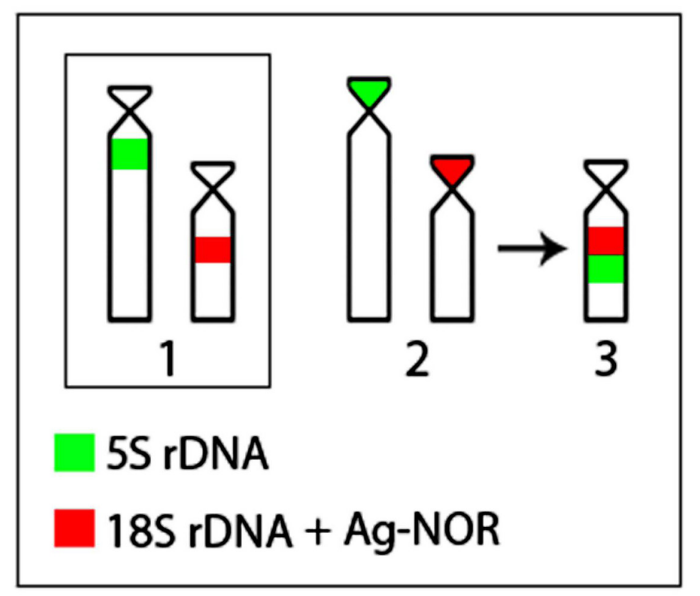

Figure 4. Idiogram representing the 3 stages of chromosomal location of ribosomal sites in Eucinostomus species. First pattern is represented by both $5 \mathrm{~S}$ and $18 \mathrm{~S}$ sites in interstitial position on different chromosome pairs; second, represented by both $5 \mathrm{~S}$ and $18 \mathrm{~S}$ sites in the terminal position on different chromosomes; and third, both $5 \mathrm{~S}$ and $18 \mathrm{~S}$ sites are colocated on a single pair in the interstitial position.

Telomeric probes have usually been employed in the identification of traces of recent evolutionary chromosomal rearrangements, as has been identified in Salmoniformes (Salvadori et al., 1995), Characiformes (Cioffi et al., 2010), and Perciformes (Gornung et al., 1998), among other groups. Mapping of repetitive sequences (TTAGGG) in the karyotypes of the 3 species indicates an exclusive location in the terminal portions of all chromosomes of the complement. The failure to detect ectopic sites and the maintenance of the basal diploid number, associated with the dynamics presented by ribosomal sequences, suggests that the distribution 
of ribosomal genes in interstitial or terminal positions may result from transposition or paracentric inversions; the latter process is rarely detected among fish (Porto-Foresti et al., 2004).

The macrokaryotypic conservatism observed in Eucinostomus, whose greatest detectable variation is related to the dynamics of ribosomal sites in the karyotype, finds support in previous evidence found in other genera of Gerreidae (Calado et al., 2013). In this karyoevolutionary context, with reduced rates of chromosomal diversification, cytogenetic analyses employing recent advances in molecular cytogenetic methods emerge as an interesting model for tracking the processes of diversification within the group.

\section{ACKNOWLEDGMENTS}

The authors thank the National Research Council (CNPq) for financial support (Process \#556793/2009-9), the Brazilian Institute of the Environment and Natural Resources (IBAMA) for granting the collection license (Process \#19135/1), and J. Garcia Jr. for taxonomic identification of specimens.

\section{REFERENCES}

Affonso PR and Galetti PM Jr (2005). Chromosomal diversification of reef fishes from genus Centropyge (Perciformes, Pomacanthidae). Genetica 123: 227-233.

Amarasinghe V and Carlson JE (1998). Physical mapping and characterization of 5S rRNA genes in Douglas-fir. J. Hered. 89: 495-500.

Arai R (2011). Fish Karyotypes: A Check List. 1st edn. Springer, Tokyo.

Calado LL, Bertollo LAC, Costa GWWF and Molina WF (2013). Cytogenetic studies of Atlantic mojarras (Perciformes - Gerreidae): chromosomal mapping of 5S and 18S ribosomal genes using double FISH. Aquac. Res. 44: 829-835.

Cioffi MB, Martins C, Centofante L, Jacobina U, et al. (2009). Chromosomal variability among allopatric populations of Erythrinidae fish Hoplias malabaricus: mapping of three classes of repetitive DNAs. Cytogenet. Genome Res. 125: 132-141.

Cioffi MB, Martins C and Bertollo LA (2010). Chromosome spreading of associated transposable elements and ribosomal DNA in the fish Erythrinus erythrinus. Implications for genome change and karyoevolution in fish. BMC Evol. Biol. 10: 271 .

Diniz D, Moreira-Filho O and Bertollo LA (2008). Molecular cytogenetics and characterization of a ZZ/ZW sex chromosome system in Triportheus nematurus (Characiformes, Characidae). Genetica 133: 85-91.

Eschmeyer WN (1998). Catalog of Fishes. 1st edn. California Academy of Science, San Francisco.

Fujiwara A, Abe S, Yamaha E, Yamazaki F, et al. (1998). Chromosomal localization and heterochromatin association of ribosomal RNA gene loci and silver-stained nucleolar organizer regions in salmonid fishes. Chromosome Res. 6: 463-471.

Gold JR, Li YC, Shipley NS and Powers PK (1990). Improved methods for working with fish chromosomes with a review of metaphase chromosome banding. J. Fish Biol. 37: 563-575.

Gornung E, Gabrielli I and Sola L (1998). Localization of the (TTAGGG)n telomeric sequence in zebrafish chromosomes. Genome 41: 136-138.

Hatanaka T and Galetti PM (2004). Mapping of the 18S and 5S ribosomal RNA genes in the fish Prochilodus argenteus Agassiz, 1829 (Characiformes, Prochilodontidae). Genetica 122: 239-244.

Howell WM and Black DA (1980). Controller silver-staining of nucleolus organizer region with protective colloidal developer: a 1-step method. Experientia 36: 1014-1015.

Ijdo JW, Wells RA, Baldini A and Reeders ST (1991). Improved telomere detection using a telomere repeat probe (TTAGGG)n generated by PCR. Nucleic Acids Res. 19: 4780.

Jacobina UP, Vicari MR, Martinez PA, Cioffi MB, et al. (2013). Atlantic moonfishes: independent pathways of karyotypic and morphological differentiation. Helgol. Mar. Res. 67: 499-506.

Lima-Filho PA, Cioffi MB, Bertollo LAC and Molina WF (2012). Chromosomal and morphological divergences in Atlantic populations of the frillfin goby Bathygobius soporator (Gobiidae, Perciformes). J. Exp. Mar. Biol. Ecol. 434: 63-70. 
Martinez PA, Jacobina UP and Molina WF (2011). Comparative cytogenetics and heterochromatic patterns in two species of the genus Acanthostracion (Ostraciidae: Tetraodontiformes). Mar. Genom. 4: 215-220.

Martins C and Galetti PM Jr (1999). Chromosomal localization of 5S rDNA genes in Leporinus fish (Anostomidae, Characiformes). Chromosome Res. 7: 363-367.

Martins C and Galetti PM Jr (2000). Conservative distribution of 5S rDNA loci in Schizodon (Pisces, Anostomidae) chromosomes. Chromosome Res. 8: 353-355.

Molina WF (2007). Fish Cytogenetics. In: Chromosomal Changes and Stasis in Marine Fish Groups (Pisano E, OzoufCostaz C, Foresti F and Kapoor BG, eds.). Science Publisher, Enfield, 69-110.

Molina WF, Alves DE, Araujo WC, Martinez PA, et al. (2010). Performance of human immunostimulating agents in the improvement of fish cytogenetic preparations. Genet. Mol. Res. 9: 1807-1814.

Molina WF, Costa GWWF, Cioffi MB and Bertollo LAC (2012a). Chromosomal differentiation and speciation in sisterspecies of Grammatidae (Perciformes) from the Western Atlantic. Helgol. Mar. Res. 66: 363-370.

Molina WF, Motta Neto CC, Sena DC, Cioffi MB, et al. (2012b). Karyoevolutionary aspects of Atlantic hogfishes (Labridae-Bodianinae), with evidence of an atypical decondensed argentophilic heterochromatin. Mar. Genomics 6: 25-31.

Morán P, Pendás AM, García-Vázquez E and Izquierdo J (1994). Genetic variation among Atlantic salmon in six Spanish rivers. J. Fish Biol. 45: 831-837.

Motta-Neto CC, Cioffi MB, Bertollo LAC and Molina WF (2011). Extensive chromosomal homologies and evidence of karyotypic stasis in Atlantic grunts of the genus Haemulon (Perciformes). J. Exp. Mar. Biol. Ecol. 401: 75-79.

Motta-Neto CC, Lima-Filho PA, Araujo WC, Bertollo LAC, et al. (2012). Differentiated evolutionary pathways in Haemulidae (Perciformes): karyotype stasis versus morphological differentiation. Rev. Fish Biol. Fish. 22: 457-465.

Nelson JS (2006). Fishes of the World. 4th edn. John Wiley and Sons, New York.

Pendás AM, Moran P, Freije JP and Garcia-Vazquez E (1994). Chromosomal mapping and nucleotide sequence of two tandem repeats of Atlantic salmon 5S rDNA. Cytogenet. Cell Genet. 67: 31-36.

Pendás AM, Moran P, Martinez JL and Garcia-Vazquez E (1995). Applications of 5S rDNA in Atlantic salmon, brown trout, and in Atlantic salmon x brown trout hybrid identification. Mol. Ecol. 4: 275-276.

Pinkel D, Straume T and Gray JW (1986). Cytogenetic analysis using quantitative, high-sensitivity, fluorescence hybridization. Proc. Natl. Acad. Sci. U. S. A. 83: 2934-2938.

Porto-Foresti F, Oliveira C, Gomes EA, Tabata YA, et al. (2004). A lethal effect associated with polymorphism of the NOR-bearing chromosomes in rainbow trout (Oncorhynchus mykiss). Genet. Mol. Biol. 27: 51-54.

Ramírez-Luna V, Navia AF and Rubio EA (2008). Food habits and feeding ecology of an estuarine fish assemblage of Northern Pacific Coast of Ecuador. Pan-Am. J. Aquat. Sci. 3: 361-372.

Ruiz-Carus R and Uribe-Alcocer M (2003). Karyotype analysis of Eucinostomus argenteus, E. gula, E. harengulus, and Eugerres plumieri (Teleostei, Gerreidae) from Florida and Puerto Rico. Environ. Biol. Fishes 67: 269-276.

Salvadori S, Deiana A, Elisabetta C, Floridia G, et al. (1995). Colocalization of (TTAGGG)n telomeric sequences and ribosomal genes in Atlantic eels. Chromosome Res. 3: 54-58.

Schweizer D and Loidl J (1987). A model for heterochromatin dispersion and the evolution of C-band patterns. Chromosomes Today 9: 61-74.

Shishido R, Sano Y and Fukui K (2000). Ribosomal DNAs: an exception to the conservation of gene order in rice genomes. Mol. Gen. Genet. 263: 586-591.

Sumner AT (1972). A simple technique for demonstrating centromeric heterochromatin. Exp. Cell Res. 75: 304-306.

Vicente VE, Jesus CM and Moreira-Filho O (2001). Chromosomal localization of 5S and 18S rRNA genes in three Parodon species (Pisces, Parodontidae).Caryologia 54: 365-369.

White TJ, Bruns T, Lee S and Taylor J (1990). PCR Protocols: a Guide to Methods and Applications. In: Amplification and Direct Sequencing of Fungal Ribosomal RNA Genes for Phylogenetics (Innis MA, Gelfand DH, Shinsky JJ and White TJ, eds.). Academic Press Inc., New York, 315-322. 